\title{
In search of synergistic effects in antioxidant capacity of combined edible mushrooms
}

\author{
BRUNO QUEIRÓS ${ }^{1,2}$, JOÃO C.M. BARREIRA ${ }^{1}$, ANA CRISTINA \\ SARMENTO $^{2} \&$ ISABEL C.F.R. FERREIRA ${ }^{1 \star}$ \\ ${ }^{1}$ CIMO, Escola Superior Agrária, Instituto Politécnico de Bragança, Campus de Santa \\ Apolónia, Bragança, Portugal, and ${ }^{2}$ CESAM, Departamento de Biologia, \\ Universidade de Aveiro, Aveiro, Portugal
}

\begin{abstract}
The antioxidant activity of different edible mushrooms was evaluated considering the different contribution of individual and combined extracts. The radical scavenging capacity was evaluated through hydrogen atom transfer and single electron transfer reaction-based assays: DPPH radical scavenging activity and reducing power, respectively. The inhibition of lipid peroxidation was studied in lipossomes solutions by the $\beta$-carotene-linoleate system. Three types of interactions (synergistic, additive and negative synergistic effects) were observed, synergism being the most abundant effect. Marasmius oreades is present in the mixtures with higher antioxidant properties and synergistic effects, while Cantharellus cibarius is present in the mixtures with lowest antioxidant properties and negative synergist effects. Two discriminant analyses were performed considering individual species in one case and mushroom mixtures in the other. The five mushroom species were clustered in five individual groups, but a similar result could not be obtained for the combined mushrooms, for which only the cases containing C. cibarius were separated in individual clusters.
\end{abstract}

Keywords: Mushrooms, antioxidant activity, phenolics, synergism, discriminant analysis

\section{Introduction}

For thousands of years, medicine and natural products have been closely linked through the use of traditional medicines and natural poisons. Natural products represent a rich source of biologically active compounds and are an example of molecular diversity, with recognized potential in drug discovery and development (Cragg et al. 1997; Grabley and Thiericke 1999; Harvey 2000; Newman et al. 2000). Mushrooms have an established history of use in traditional oriental medicine, where most medicinal mushroom preparations are regarded as a tonic - that is, as having beneficial health effects without negative side-effects, and can be used on a regular, ongoing basis without harm. Often, blends of various medicinal mushrooms are used for maximum benefit (Mizuno 1995; Wasser and Weis, 1999).

Mushrooms are rich sources of antioxidant compounds, mainly phenolic compounds (phenolic acids and flavonoids), followed by tocopherols, ascorbic acid 
and carotenoids as was earlier described by our research group (Ferreira et al. 2009) and by others (Cheung and Cheung 2005; Elmastas et al. 2007; Tsai et al. 2007; Kim et al. 2008; Lee et al. 2008). They may provide beneficial effects on human health either directly as antioxidants or through prevention of alterations underlying major pathological states related to oxidative stress such as cancer, diabetes, neurodegenerative diseases, cardiovascular diseases and metabolic syndrome (Zhou et al. 2005).

Phytochemical extracts from fruits and vegetables have strong antioxidant and antiproliferative activities, and the major part of total antioxidant activity is from the combination of phytochemicals, resulting in additive and/or synergistic effects. This explains why no single antioxidant can replace the combination of natural phytochemicals in foods and achieve their health benefits. Therefore, the evidence suggests that antioxidants are best acquired through whole food consumption, not from expensive dietary supplements (Liu 2004).

Total antioxidant capacity in fruits, vegetables and their processing products is attributed to three different types of interaction: synergistic effect, as detected by Vinson et al. (2001) among phenols extracted from several fruits and from the plant Glossogyne tenuifolia (Hsu et al. 2005); negative synergism, such as that observed for phenolic components from Dalbergis odorifera when mixed with either 2-tert-butyl-4methoxyphenol (BHT) or $\alpha$-tocopherol (Wang et al. 2000) or in a mixture of three monophenols, catechin, resveratrol, and quercetin (Pinelo et al. 2004); and additive effect, such as that observed between sweetpotato anthocyanins and hydroxycinnamic acids (Philpott et al. 2004) or in a mixture of two or three phenolics combined (Heo et al. 2007).

Boletus edulis, Calocybe gambosa, Cantharellus cibarius, Craterellus cornucopioides and Marasmius oreades were recently analysed for their nutrients (ash, fat, proteins, and carbohydrates including sugars), nutraceuticals (fatty acids, tocopherols, ascorbic acid and carotenoids) and antimicrobial activity (Barros et al. 2008a), but there are no reports on their antioxidant activity. Although it has already been demonstrated that many mushrooms have antioxidant activity and different antioxidant compounds, nothing is reported about the synergism related to the use of combined mushrooms species. Accordingly, in the present work, the antioxidant properties of individual samples and of combined mushroom species were evaluated through chemical and biochemical assays: 2,2-diphenyl-1-picrylhydrazyl (DPPH) radical scavenging activity, reducing power, and lipid peroxidation inhibition. Furthermore, this is the first study reporting antioxidant activity of $C$. gambosa, C. cornucopioides and M. oreades.

\section{Materials and methods}

Mushroom species and sample preparation

B. edulis Fr. (Be), C. gambosa (Fr.) Donk (Cg), C. cibarius L. ex Fr. (Cci), C. cornucopioides Pers. (Cco), and M. oreades (Bolt. ex Fr.) Fr. (Mo) were commercial dried samples obtained in local supermarkets. The samples ( $3 \mathrm{~g}$ for the assays with the single species, and $1.5 \mathrm{~g}$ each mushroom for the assays with the combined species) were extracted by stirring with $100 \mathrm{ml}$ methanol for $24 \mathrm{~h}\left(25^{\circ} \mathrm{C}\right.$ at $\left.150 \mathrm{rpm}\right)$ and subsequently filtered through Whatman No. 4 paper. The residue was then extracted with two additional $100 \mathrm{ml}$ portions of methanol. The combined methanolic extracts were evaporated at $40^{\circ} \mathrm{C}$ to dryness and were redissolved in methanol at a concentration of $50 \mathrm{mg} / \mathrm{ml}$, and stored at $4{ }^{\circ} \mathrm{C}$ until analysis. 


\section{Standards and reagents}

Standards 2-tert-butyl-4-methoxyphenol (BHA), tertbutylhydroquinone (TBHQ), Lascorbic acid, $\alpha$-tocopherol, gallic acid and $(+)$-catechin were purchased from Sigma (St Louis, MO, USA). DPPH was obtained from Alfa Aesar (Ward Hill, MA, USA). All other chemicals were obtained from Sigma Chemical Co. Methanol 99.99\% was obtained from Pronalab (Lisbon, Portugal). Water was treated in a Milli-Q water purification system (TGI Pure Water Systems, Brea, CA, USA).

\section{Phenolics}

For the phenolics content determination, the sample $(1 \mathrm{ml})$ was mixed with Folin and Ciocalteu's phenol reagent $(1 \mathrm{ml})$. After $3 \mathrm{~min}$, saturated sodium carbonate solution $(1 \mathrm{ml})$ was added to the mixture and adjusted to $10 \mathrm{ml}$ with distilled water. The reaction was kept in the dark for $90 \mathrm{~min}$, after which the absorbance was read at $725 \mathrm{~nm}$ (Analytik Jena 200-2004 spectrophotometer, Jena, Germany) according to Barros et al. (2008b). Gallic acid was used to calculate the standard curve $(0.01-0.4 \mathrm{mM} ; Y=$ $\left.2.8557 X-0.0021 ; R^{2}=0.9999\right)$ and the results were expressed as milligrams of gallic acid equivalents per gram of extract.

\section{Antioxidant activity}

Chemical and biochemical assays already described by us in previous studies (Barros et al. 2008b), were applied to evaluate the antioxidant activity of the individual mushrooms and of combined mixtures.

DPPH radical-scavenging activity. Various concentrations of the extracts $(0.3 \mathrm{ml})$ were mixed with $2.7 \mathrm{ml}$ methanolic solution of DPPH radicals $\left(6 \times 10^{-5} \mathrm{~mol} / \mathrm{l}\right)$. The mixture was shaken vigorously and left to stand for $60 \mathrm{~min}$ in the dark (until stable absorption values were obtained). The reduction of the DPPH radical was determined by measuring the absorption at $517 \mathrm{~nm}$. The radical scavenging activity (RSA) was calculated as a percentage of DPPH discoloration using the equation: $\%$ RSA = [ $\left.\left(A_{\mathrm{DPPH}}-A_{\mathrm{S}}\right) / \mathrm{A}_{\mathrm{DPPH}}\right] \times 100$, where $A_{\mathrm{S}}$ is the absorbance of the solution when the sample extract has been added and $A_{\mathrm{DPPH}}$ is the absorbance of the DPPH solution. The extract concentration providing $50 \%$ of radicals scavenging activity $\left(\mathrm{EC}_{50}\right)$ was calculated by interpolation from the graph of RSA percentage against extract concentration. BHA and $\alpha$-tocopherol were used as standards.

Reducing power. Various concentrations of the extracts $(2.5 \mathrm{ml})$ were mixed with sodium phosphate buffer $(2.5 \mathrm{ml}$ of $200 \mathrm{mM} \mathrm{pH} \mathrm{6.6)}$ and potassium ferricyanide ( $1 \%$ $\mathrm{w} / \mathrm{v}, 2.5 \mathrm{ml}$ ). The mixture was incubated at $50^{\circ} \mathrm{C}$ for $20 \mathrm{~min}$. After tricloroacetic acid $(10 \%, 2.5 \mathrm{ml})$ was added, the mixture was centrifuged at $1,000 \mathrm{rpm}$ for $8 \mathrm{~min}$ (K24OR-2003 refrigerated centrifuge, Centurion Scientific, Arundel, UK). The upper layer $(5 \mathrm{ml})$ was mixed with deionized water $(5 \mathrm{ml})$ and ferric chloride $(0.1 \%, 1$ $\mathrm{ml}$ ), and the absorbance was measured spectrophotometrically at $700 \mathrm{~nm}$ : higher absorbances indicate higher reducing power. The extract concentration providing $50 \%$ of absorbance $\left(\mathrm{EC}_{50}\right)$ was calculated by interpolation from the graph of absorbance at $700 \mathrm{~nm}$ against extract concentration. BHA and $\alpha$-tocopherol were used as standards. 
Inhibition of $\beta$-carotene bleaching. The antioxidant activity of the extracts was evaluated by the $\beta$-carotene linoleate model system. A solution of $\beta$-carotene was prepared by dissolving $\beta$-carotene $(2 \mathrm{mg})$ in chloroform $(10 \mathrm{ml})$. Two millilitres of this solution were added to a $100 \mathrm{ml}$ round-bottom flask. After the chloroform was removed at $40^{\circ} \mathrm{C}$ under vacuum, linoleic acid (40 mg), Tween 80 emulsifier $(400 \mathrm{mg})$, and distilled water $(100 \mathrm{ml})$ were added to the flask and vigorously shaken. Aliquots $(4.8 \mathrm{ml})$ of this emulsion were transferred into different test tubes containing different concentrations $(0.2 \mathrm{ml})$ of the extracts. The tubes were shaken and incubated at $50^{\circ} \mathrm{C}$ in a water bath. As soon as the emulsion was added to each tube, the zero time absorbance at $470 \mathrm{~nm}$ was measured. Absorbance readings were then recorded at 20-min intervals until the control sample had changed colour. A blank, devoid of $\beta$-carotene, was used for background subtraction. Lipid peroxidation inhibition was calculated using the following equation: ( $\beta$-carotene content after $2 \mathrm{~h}$ of assay/initial $\beta$-carotene content) $\mathrm{x} 100$. The extract concentration providing the $\mathrm{EC}_{50}$ value was calculated by interpolation from the graph of antioxidant activity percentage against extract concentration. TBHQ was used as standard.

\section{Statistical analysis}

The assays were carried out in triplicate and the results are expressed as mean values \pm standard deviation. The statistical differences represented later in Table I and II were obtained through one-way analysis of variance (ANOVA) followed by Tukey's honestly significant difference post-hoc test with $\alpha=0.05$, coupled with Welch's statistic.

In order to determine which variables discriminate between the five naturally occurring groups considering the five tested species (Be, Cci, Cco, Mo and $\mathrm{Cg}$ ), as well as the groups formed by the assayed mixtures $(\mathrm{Be}+\mathrm{Cci}, \mathrm{Be}+\mathrm{Cco}, \mathrm{Be}+\mathrm{Mo}, \mathrm{Be}+$ $\mathrm{Cg}, \mathrm{Cci}+\mathrm{Cco}, \mathrm{Cci}+\mathrm{Mo}, \mathrm{Cci}+\mathrm{Cg}, \mathrm{Cco}+\mathrm{Mo}, \mathrm{Cco}+\mathrm{Cg}$ and $\mathrm{Mo}+\mathrm{Cg}$ ), a discriminant function analysis was carried out, following the stepwise method, where the model of discrimination is built step by step. At each step, all variables are reconsidered to find which one will contribute most to the discrimination between groups. That variable will then be included in the model, restarting the process. The values of $F$ to enter (3.84) and $F$ to remove (2.71) are the guidelines of the stepwise procedure. A variable is entered into the model if its $F$ value is greater than the $F$-enter value, and it is removed if the $F$ value is less than the $F$-remove value. $F$-enter must be greater than $F$-remove, and both values must be positive. The $F$-value for a variable

Table I. Experimental values of phenolics $(\mathrm{mg} / \mathrm{g})$ and antioxidant activity $\mathrm{EC}_{50}(\mathrm{mg} / \mathrm{ml})$ of the individual mushroom species.

\begin{tabular}{llccc}
\hline Species & Phenolics & $\begin{array}{c}\text { DPPH scavenging } \\
\text { activity }\end{array}$ & $\begin{array}{c}\text { Reducing } \\
\text { power }\end{array}$ & $\begin{array}{c}\text { Lipid peroxidation } \\
\text { inhibition }\end{array}$ \\
\hline B. edulis $(\mathrm{Be})$ & $5.03 \pm 0.07^{\mathrm{A}}$ & $2.55 \pm 0.07^{\mathrm{B}}$ & $1.21 \pm 0.05^{\mathrm{E}}$ & $1.09 \pm 0.27^{\mathrm{E}}$ \\
C. gambosa $(\mathrm{Cg})_{\text {C cibarius }(\mathrm{Cci})}$ & $1.70 \pm 0.63^{\mathrm{D}}$ & $7.14 \pm 0.63^{\mathrm{A}}$ & $4.31 \pm 0.03^{\mathrm{B}}$ & $2.77 \pm 0.02^{\mathrm{B}}$ \\
C. cornucopioides $(\mathrm{Cco})_{\text {M. }}$ & $0.88 \pm 0.09^{\mathrm{E}}$ & $7.49 \pm 1.87^{\mathrm{A}}$ & $5.89 \pm 0.07^{\mathrm{A}}$ & $3.64 \pm 0.05^{\mathrm{A}}$ \\
Mo) & $2.13 \pm 0.48^{\mathrm{C}}$ & $6.33 \pm 0.48^{\mathrm{A}}$ & $3.69 \pm 0.03^{\mathrm{C}}$ & $1.79 \pm 0.51^{\mathrm{C}}$ \\
\hline
\end{tabular}

Data presented as mean \pm standard deviation; $n=3$. In each column, different superscript uppercase letters indicate significant differences $(P<0.05)$. 
Table II. Experimental values of phenolics $(\mathrm{mg} / \mathrm{g})$ and antioxidant activity $\mathrm{EC}_{50}(\mathrm{mg} / \mathrm{ml})$ of the combined mushroom species.

\begin{tabular}{lcccc}
\hline Sample & Phenolics & $\begin{array}{c}\text { DPPH scavenging } \\
\text { activity }\end{array}$ & $\begin{array}{c}\text { Reducing } \\
\text { power }\end{array}$ & $\begin{array}{c}\text { Lipid peroxidation } \\
\text { inhibition }\end{array}$ \\
\hline $\mathrm{Be}+\mathrm{Cci}$ & $2.25 \pm 0.10^{\mathrm{D}}$ & $5.78 \pm 0.20^{\mathrm{B}}$ & $2.20 \pm 0.06^{\mathrm{F}}$ & $1.76 \pm 0.01^{\mathrm{C}}$ \\
$\mathrm{Be}+\mathrm{Cco}$ & $4.04 \pm 0.34^{\mathrm{C}}$ & $4.82 \pm 0.93^{\mathrm{C}}$ & $2.25 \pm 0.03^{\mathrm{EF}}$ & $1.40 \pm 0.12^{\mathrm{D}}$ \\
$\mathrm{Be}+\mathrm{Mo}$ & $4.59 \pm 0.11^{\mathrm{A}}$ & $4.05 \pm 0.11^{\mathrm{C}}$ & $1.81 \pm 0.01^{\mathrm{H}}$ & $1.27 \pm 0.03^{\mathrm{DE}}$ \\
$\mathrm{Be}+\mathrm{Cg}$ & $3.69 \pm 0.40^{\mathrm{C}}$ & $4.54 \pm 0.20^{\mathrm{C}}$ & $2.25 \pm 0.02^{\mathrm{EF}}$ & $1.13 \pm 0.03^{\mathrm{EF}}$ \\
$\mathrm{Cci}+\mathrm{Cco}$ & $0.80 \pm 0.17^{\mathrm{E}}$ & $7.86 \pm 1.44^{\mathrm{A}}$ & $6.62 \pm 0.18^{\mathrm{A}}$ & $3.32 \pm 0.17^{\mathrm{A}}$ \\
$\mathrm{Cci}+\mathrm{Mo}$ & $1.98 \pm 0.13^{\mathrm{D}}$ & $7.60 \pm 0.57^{\mathrm{A}}$ & $3.38 \pm 0.03^{\mathrm{C}}$ & $1.86 \pm 0.10^{\mathrm{C}}$ \\
$\mathrm{Cci}+\mathrm{Cg}$ & $1.11 \pm 0.14^{\mathrm{E}}$ & $7.45 \pm 0.11^{\mathrm{A}}$ & $5.73 \pm 0.26^{\mathrm{B}}$ & $2.92 \pm 0.02^{\mathrm{B}}$ \\
$\mathrm{Cco}+\mathrm{Mo}$ & $4.84 \pm 0.09^{\mathrm{A}}$ & $4.00 \pm 0.06^{\mathrm{C}}$ & $2.03 \pm 0.04^{\mathrm{G}}$ & $1.06 \pm 0.04^{\mathrm{F}}$ \\
$\mathrm{Cco}+\mathrm{Cg}$ & $4.13 \pm 0.55^{\mathrm{BC}}$ & $4.22 \pm 0.31^{\mathrm{C}}$ & $2.38 \pm 0.03^{\mathrm{DE}}$ & $1.12 \pm 0.02^{\mathrm{EF}}$ \\
$\mathrm{Mo}+\mathrm{Cg}$ & $4.51 \pm 0.43^{\mathrm{AB}}$ & $4.90 \pm 0.23^{\mathrm{BC}}$ & $2.53 \pm 0.02^{\mathrm{D}}$ & $1.27 \pm 0.04^{\mathrm{DE}}$ \\
\hline
\end{tabular}

Data presented as mean \pm standard deviation; $n=3$. In each column, different superscript uppercase letters indicate significant differences $(P<0.05)$.

indicates its statistical significance in the discrimination between groups. Discriminant analysis defines an optimal combination of varieties in a way that the first function furnishes the most general discrimination between groups, the second provides the second most, and so on (Benitez et al. 2006).

These treatments were carried out using SPSS version 16.0 software (Chicago, USA).

\section{Results and discussion}

The antioxidant activity of many different mushrooms has been demonstrated and correlated to different antioxidant compounds (Ferreira et al. 2009). Nevertheless, there are no reports considering mixtures of mushrooms and analysis of the types of interactions (synergism, additive or negative synergism effects) inherent to their antioxidant behaviour. Due to the chemical diversity of antioxidant compounds present in food, it is unrealistic to separate each antioxidant component and study it individually. In addition, levels of single antioxidants in food do not necessarily reflect their total antioxidant capacity because of the possible synergistic interactions among the antioxidant compounds in a food mixture (Magalhães et al. 2008).

To screen the antioxidant properties, hydrogen atom transfer and single electron transfer reaction-based assays were performed: scavenging activity on DPPH radicals (measuring the decrease in DPPH radical absorption after exposure to radical scavengers) and reducing power (measuring the conversion of a $\mathrm{Fe}^{3+} /$ ferricyanide complex to the ferrous form). The inhibition of lipid peroxidation was evaluated through the inhibition of $\beta$-carotene bleaching (by neutralizing the linoleate-free radical and other free radicals formed in the liposome solutions that attack the highly unsaturated $\beta$-carotene models).

The phenolic content and antioxidant activity $\mathrm{EC}_{50}$ values of the edible mushrooms B. edulis, C. gambosa, C. cibarius, C. cornucopioides and $M$. oreades are presented in Table I. All of the species revealed antioxidant properties $\left(\mathrm{EC}_{50}<7.5 \mathrm{mg} / \mathrm{ml}\right)$, in the order $\mathrm{Be}>\mathrm{Mo}>\mathrm{Cco}>\mathrm{Cg}>\mathrm{Cci}$. B. edulis was the most effective species in all the assays $\left(\mathrm{EC}_{50}<2.6 \mathrm{mg} / \mathrm{ml}\right)$, also revealing the highest phenolic content $(5.03 \pm 0.07$ $\mathrm{mg} / \mathrm{g}$; Table I). In a previous study (Barros et al. 2008a) we had reported that this 
mushroom revealed to possess the highest tocopherol content (powerful antioxidants) and interesting nutritional properties with high mineral contents $(7.07 \mathrm{mg} / 100 \mathrm{~g}$, dry weight), energetic value $(1,671.83 \mathrm{~kJ} / 100 \mathrm{~g})$ due to the contribution of carbohydrates $(71.15 \mathrm{~g} / 100 \mathrm{~g})$, and high levels of unsaturated fatty acids $(85 \%)$ relative to saturated fatty acids (15\%). It also revealed a strong antimicrobial activity against Staphylococcus aureus, with minimal inhibitory concentrations lower than the standard ampicillin. Other authors reported slightly higher phenolic contents in samples of $B$. edulis from India (8.4 mg/g; Puttaraju et al. 2006) and Taiwan $(5.73 \mathrm{mg} / \mathrm{g}$; Tsai et al. 2007). Portuguese $B$. edulis methanolic extract revealed higher reducing power $\left(\mathrm{EC}_{50}=1.21\right.$ $\mathrm{mg} / \mathrm{ml})$ but lower DPPH scavenging activity $(2.55 \mathrm{mg} / \mathrm{ml})$ than the ethanolic extract from Taiwan $(8.98 \mathrm{mg} / \mathrm{ml}$ and $1.75 \mathrm{mg} / \mathrm{ml}$, respectively) (Tsai et al. 2007).

C. cibarius proved to have the worst antioxidant capacity (highest $\mathrm{EC}_{50}$ values), which is in agreement with its lower phenolic $(0.88 \pm 0.09 \mathrm{mg} / \mathrm{g}$; Table I) and tocopherol contents (Barros et al. 2008a). Despite its low antioxidant activity, this mushroom revealed strong antimicrobial activity against Bacillus subtilis and $S$. aureus (Barros et al. 2008a). Puttaraju et al. (2006) also reported B. edulis as having high antioxidant activity and $C$. cibarius as having low antioxidant activity. For C. gambosa, $C$. cornucopioides and $M$. oreades, this is the first report revealing their antioxidant properties.

The phenolic contents and antioxidant activity $\mathrm{EC}_{50}$ values for the two-mushroom mixtures are presented in Table II. The best mixtures, regarding these parameters, were $\mathrm{Be}+\mathrm{Mo}$ and $\mathrm{Cco}+\mathrm{Mo}$ (highest phenolic content and lowest antioxidant activity $\mathrm{EC}_{50}$ values), while $\mathrm{Cci}+\mathrm{Cco}, \mathrm{Cci}+\mathrm{Cg}, \mathrm{Cci}+\mathrm{Mo}$ and $\mathrm{Cci}+\mathrm{Be}$ were revealed to be the worst mixtures. $M$. oreades is present in the best mixtures while $C$. cibarius is present in all of the worst mixtures.

The types of interactions (synergism, additive or negative synergism effects) observed in the antioxidant activity of the mushrooms mixtures are presented in Table III. For the DPPH radical scavenging activity assay, it negative synergism (depletion of antioxidant capacity) was observed in $50 \%$ of the mixtures. A synergistic effect was obtained in the $\mathrm{Be}+\mathrm{Cg}$, $\mathrm{Cco}+\mathrm{Mo}$ and $\mathrm{Cco}+\mathrm{Cg}$ mixtures, while $\mathrm{Cci}+\mathrm{Cg}$ and $\mathrm{Mo}+\mathrm{Cg}$ revealed additive effects. Considering the reducing power assay, the synergism was the main effect, being observed in $70 \%$ of the mixtures. The mixtures $\mathrm{Cci}+\mathrm{Cco}, \mathrm{Cci}+\mathrm{Cg}$ and $\mathrm{Be}+\mathrm{Mo}$ presented a negative synergism. Once more, the synergist effect predominated in the lipid peroxidation assay, being observed in $70 \%$ of the mixtures. $\mathrm{Be}+\mathrm{Cco}$ and $\mathrm{Be}+\mathrm{Mo}$ revealed an additive effect, and only one mixture, $\mathrm{Cci}+\mathrm{Cco}$, revealed negative synergism (Table III).

Overall, $\mathrm{Cco}+\mathrm{Mo}$ (Figure 1$), \mathrm{Be}+\mathrm{Cg}$ and $\mathrm{Cco}+\mathrm{Cg}$ revealed synergist effects in all of the antioxidant activity assays. These mixtures also presented the highest phenolic contents and better antioxidant properties, as was already discussed and as can be observed in Table II. The mixture $\mathrm{Mo}+\mathrm{Cg}$ revealed synergism in all the assays with the exception for the DPPH radical scavenging activity, where it was observed a negative synergism. Only the Cci + Cco mixture (Figure 2) revealed negative synergist effects in all of the antioxidant activity assays, which is in agreement with its lowest phenolic contents and worse antioxidant properties (Table II). For the other mixtures that revealed low antioxidant activity, $\mathrm{Cci}+\mathrm{Cg}, \mathrm{Cci}+\mathrm{Mo}$ and $\mathrm{Cci}+\mathrm{Be}$, a negative synergism was observed in one of the assays (reducing power assay for $\mathrm{Cci}+\mathrm{Cg}$ and $\mathrm{DPPH}$ assay for the other mixtures). 
Table III. Theoretical ${ }^{\mathrm{a}}$ versus experimental values of antioxidant activity $\mathrm{EC}_{50}(\mathrm{mg} / \mathrm{ml})$ of the combined mushroom species.

\begin{tabular}{|c|c|c|c|c|c|c|c|c|c|}
\hline \multirow[b]{2}{*}{ Species } & \multicolumn{2}{|c|}{ DPPH scavenging activity } & \multicolumn{4}{|c|}{ Reducing power } & \multicolumn{3}{|c|}{ Lipid peroxidation activity } \\
\hline & Theoretical & Experimental & Effect & Theoretical & Experimental & Effect & Theoretical & Experimental & Effect \\
\hline $\mathrm{Be}+\mathrm{Cci}$ & 5.02 & 5.78 & NS & 3.55 & 2.20 & $\mathrm{~S}$ & 2.37 & 1.76 & $\mathrm{~S}$ \\
\hline $\mathrm{Be}+\mathrm{Cco}$ & 4.44 & 4.82 & NS & 2.45 & 2.25 & $S$ & 1.44 & 1.40 & A \\
\hline $\mathrm{Be}+\mathrm{Mo}$ & 2.66 & 4.05 & NS & 1.62 & 1.81 & NS & 1.33 & 1.27 & A \\
\hline $\mathrm{Be}+\mathrm{Cg}$ & 4.84 & 4.54 & $S$ & 2.76 & 2.25 & $S$ & 1.93 & 1.13 & $S$ \\
\hline $\mathrm{Cci}+\mathrm{Cco}$ & 6.91 & 7.86 & NS & 4.79 & 6.62 & NS & 2.72 & 3.32 & NS \\
\hline $\mathrm{Cci}+\mathrm{Mo}$ & 5.13 & 7.60 & NS & 3.96 & 3.38 & $S$ & 2.61 & 1.86 & $S$ \\
\hline $\mathrm{Cci}+\mathrm{Cg}$ & 7.31 & 7.45 & A & 5.10 & 5.73 & NS & 3.21 & 2.92 & $S$ \\
\hline $\mathrm{Cco}+\mathrm{Mo}$ & 4.55 & 4.00 & $\mathrm{~S}$ & 2.86 & 2.03 & $S$ & 1.68 & 1.06 & $S$ \\
\hline $\mathrm{Cco}+\mathrm{Cg}$ & 6.73 & 4.22 & $S$ & 4.00 & 2.38 & $S$ & 2.28 & 1.12 & $S$ \\
\hline $\mathrm{Mo}+\mathrm{Cg}$ & 4.96 & 4.90 & A & 3.17 & 2.53 & $S$ & 2.17 & 1.27 & $S$ \\
\hline
\end{tabular}

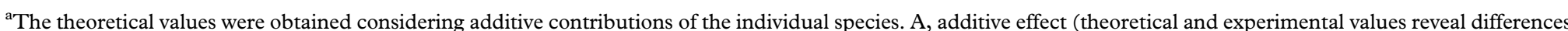
lower than $5 \%$ ); S, synergistic effect (experimental values are more than $5 \%$ lower for $\mathrm{EC}_{50}$ when compared with theoretical values); NS, negative synergistic (antagonist) effect (experimental values are more than $5 \%$ higher for $\mathrm{EC}_{50}$ when compared with theoretical values). 

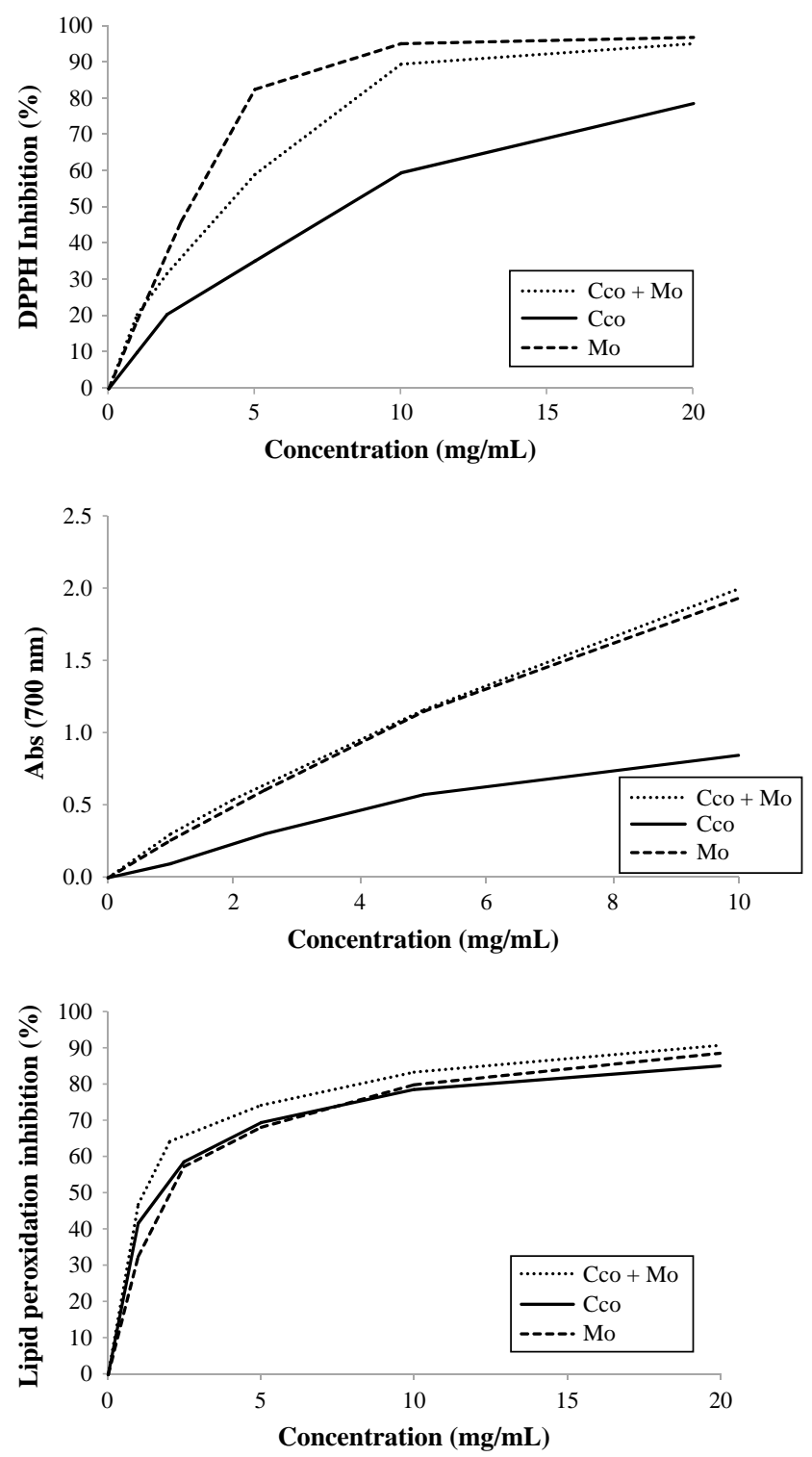

Figure 1. Synergistic effect in DPPH scavenging inhibition, reducing power and lipid peroxidation inhibition: the example of the $C$. cornucopioides $+M$. oreades mixture.

Table IV and V present, respectively, the results from applying the algorithm for selecting mushroom species and mushroom mixtures according to the phenolic content, DPPH scavenging activity, reducing power and lipid peroxidation inhibition. Wilk's Lambda is a variable selection method for stepwise discriminant analysis that chooses variables for entry into the equation on the basis of how much they lower Wilk's Lambda (Benitez et al. 2006). At each step, the variable that minimizes the overall Wilk's Lambda is entered. 

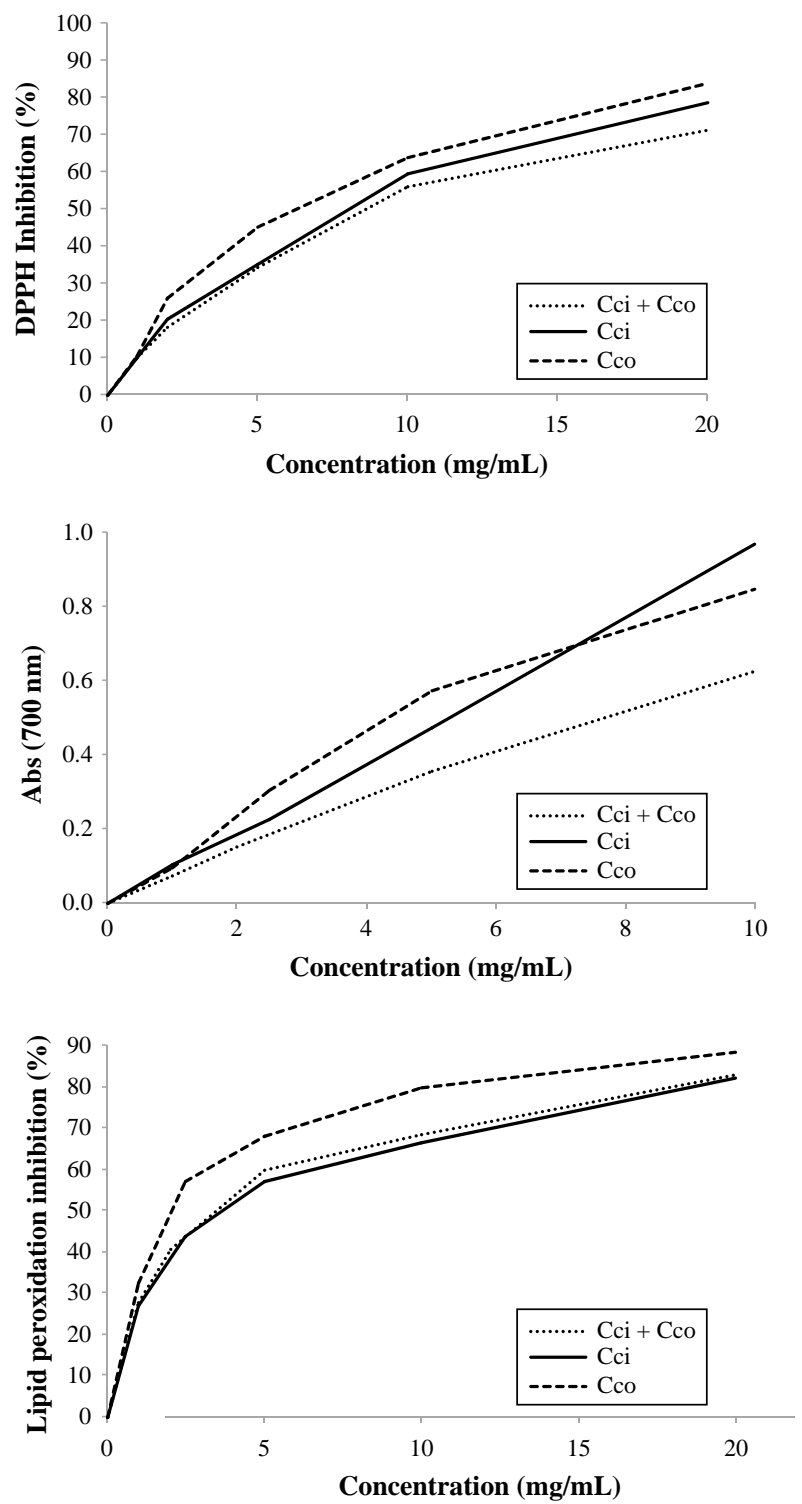

Figure 2. Negative synergistic effect in DPPH scavenging inhibition, reducing power and lipid peroxidation inhibition: the example of the $C$. cibarius $+C$. cornucopioides mixture.

Table IV. Discriminant analysis parameters for individual mushroom species.

\begin{tabular}{lccccc}
\hline & $\begin{array}{c}\text { Wilks' } \\
\text { Lambda }\end{array}$ & $F$-remove (2.71) & $P$-level & Tolerance & $\begin{array}{c}1-\text { tolerance } \\
\left(R^{2}\right)\end{array}$ \\
\hline Reducing power & 0.0018 & $193,660.2897$ & 0.0000 & 0.9999 & 0.0001 \\
Phenolic content & 0.0000 & 40.5665 & 0.0000 & 0.9152 & 0.0848 \\
Lipid peroxidation inhibition & 0.0000 & 10.2192 & 0.0000 & 0.6122 & 0.3878 \\
DPPH radical scavenging activity & 0.0000 & 6.4332 & 0.0000 & 0.6570 & 0.3430 \\
\hline
\end{tabular}


Table V. Discriminant analysis parameters combined mushroom species.

\begin{tabular}{lcrrrr}
\hline & $\begin{array}{c}\text { Wilks' } \\
\text { Lambda }\end{array}$ & $\begin{array}{c}\text { F-remove } \\
(2.71)\end{array}$ & $P$-level & Tolerance & $\begin{array}{c}1-\text { tolerance } \\
\left(R^{2}\right)\end{array}$ \\
\hline Reducing power & 0.0021 & 235.2535 & 0.0000 & 0.9028 & 0.0972 \\
Phenolic content & 0.0003 & 29.6423 & 0.0000 & 0.9669 & 0.0331 \\
Lipid peroxidation inhibition & 0.0002 & 17.1959 & 0.0000 & 0.9460 & 0.0540 \\
DPPH radical scavenging activity & 0.0002 & 8.9159 & 0.0000 & 0.8973 & 0.1027 \\
\hline
\end{tabular}

Tolerance is the proportion of a variable's variance not accounted by other independent variables in the equation. If it is low, it will contribute with little information to the model and might cause problems.

Regarding single mushroom species, the discriminant analysis defined four dimensions, but only the first two were plotted (Figure 3). The first discriminant analysis dimension separates all species (means of the canonical variance $(\mathrm{MCV}): \mathrm{Be}=-1027) .765, \mathrm{Cg}=409.600, \mathrm{Cci}=1143.484, \mathrm{Cco}=124.693$ and $\mathrm{Mo}=-650.011$ ), and was more strongly correlated with reducing power (Table VI).

In the case of mushroom mixtures, discriminant analysis also defined four dimensions, being $99.6 \%$ of the observed variance explained by the first two (Figure 4). The first dimension separates mainly $\mathrm{Be}+\mathrm{Cci}, \mathrm{Cci}+\mathrm{Cco}, \mathrm{Cci}+\mathrm{Mo}$ and $\mathrm{Cci}+\mathrm{Cg}$ from the remaining mixtures $(\mathrm{MCV}: \mathrm{Be}+\mathrm{Cci}=-7.068, \mathrm{Cci}+\mathrm{Cco}=$ $40.844, \mathrm{Cci}+\mathrm{Mo}=4.031, \mathrm{Cci}+\mathrm{Cg}=30.854)$, proving to be more accurately related with reducing power (Table VII). The second discriminant analysis dimension confirmed the separation of $\mathrm{Be}+\mathrm{Cci}$ and $\mathrm{Cci}+\mathrm{Mo}(\mathrm{MCV}: \mathrm{Be}+\mathrm{Cci}=-6.145$, $\mathrm{Cci}+\mathrm{Mo}=-4.263$, and $\mathrm{Cci}+\mathrm{Cg}=30.854)$, and was more powerfully associated with phenolic content (Table VII).

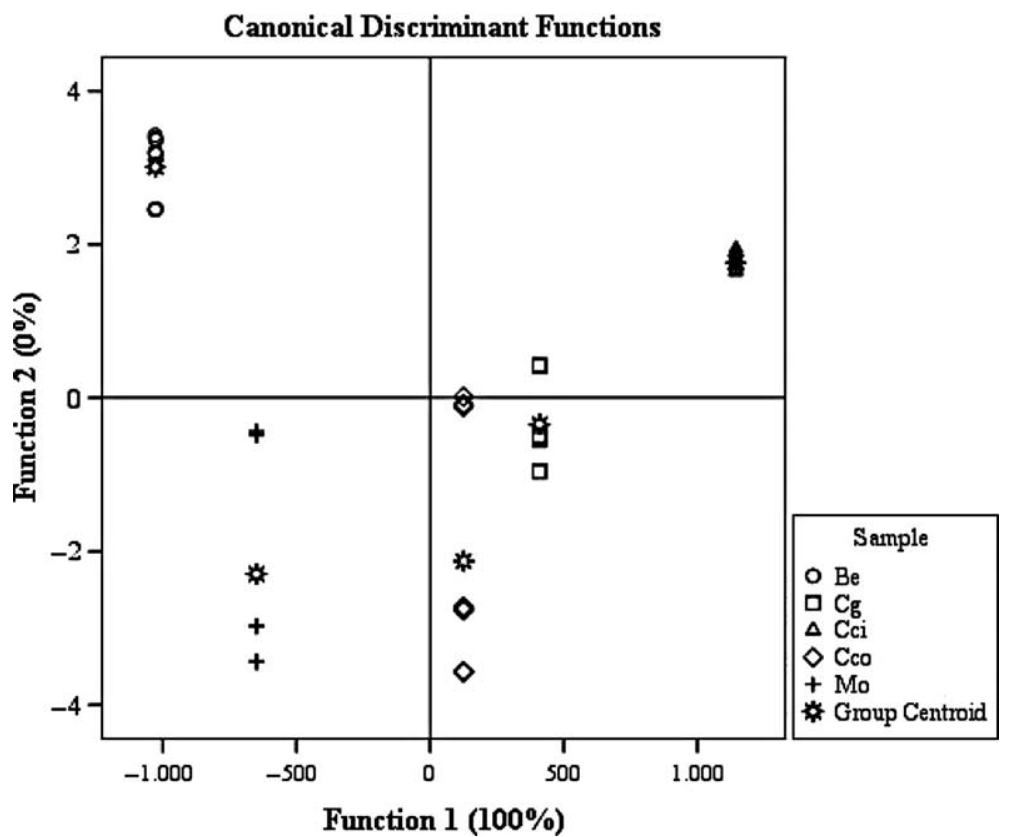

Figure 3. Canonical analysis of the individual mushroom species. 
Table VI. Correlations between discriminating variables and standardized canonical discriminant functions for individual mushroom species.

\begin{tabular}{lrrrr}
\hline & \multicolumn{4}{c}{ Function } \\
\cline { 2 - 5 } & \multicolumn{1}{c}{1} & 2 & 3 & 4 \\
\hline Reducing power & $1.0000^{\mathrm{a}}$ & -0.0016 & -0.0056 & -0.0040 \\
Phenolic content & -0.0085 & $0.8732^{\mathrm{a}}$ & -0.4794 & 0.0873 \\
Lipid peroxidation inhibition & 0.0039 & 0.2061 & $0.8434^{\mathrm{a}}$ & -0.4963 \\
DPPH radical scavenging activity & 0.0029 & -0.0742 & -0.0819 & $0.9939^{\mathrm{a}}$ \\
\hline
\end{tabular}

Variables are ordered by absolute size of correlation within function. ${ }^{a}$ Largest absolute correlation between each variable and any discriminant function.

The different behaviour could probably be explained on the basis of the chemical nature and reactivity of the compounds present in the mixtures, such as tocopherols, ascorbic acid, sugars and, mostly, phenolic compounds. These individual compounds can suffer polymerization and other reactions that promote important structural changes and, as a consequence, variations in their antioxidant activity (Pinelo et al. 2004). For example, the radical scavenging capacity of phenolic compounds is attributed to their hydrogen-donating ability: the higher the number of hydroxyl groups, the higher the possibility of free radical scavenging activity. The availability of the hydroxyl groups closely depends on both chemical structure and spatial conformation, which can modify the reactivity of the molecules. However, when the degree of polymerization exceeds a critical value, the increased molecular complexity promotes a decrease in antioxidant capacity, probably because of the steric hindrance, which reduces the availability of the hydroxyl groups (Pinelo et al. 2004).

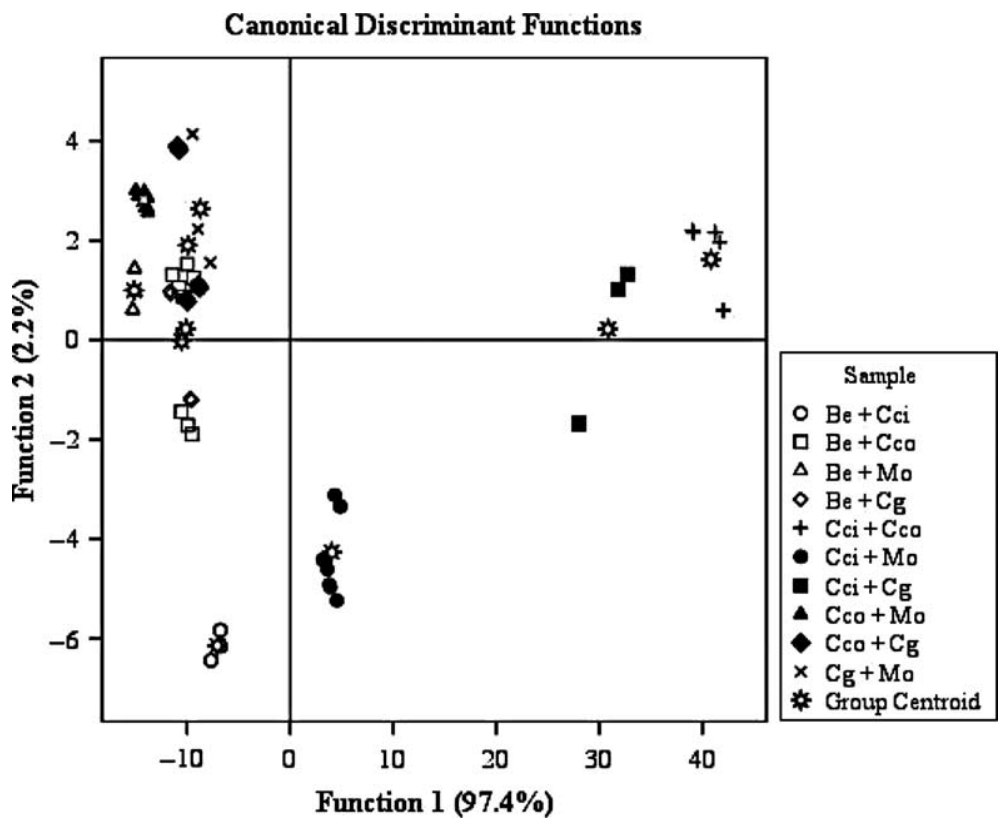

Figure 4. Canonical analysis of the combined mushrooms. 
Table VII. Correlations between discriminating variables and standardized canonical discriminant functions for combined mushroom species.

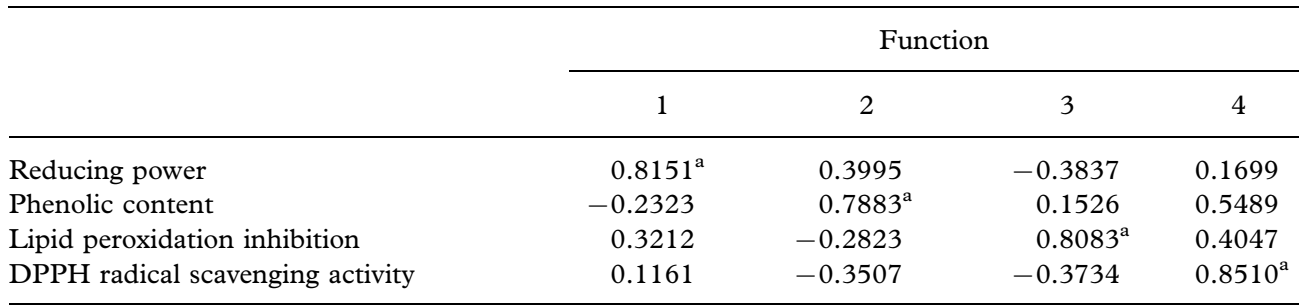

Variables are ordered by absolute size of correlation within function. ${ }^{\text {a }}$ Largest absolute correlation between each variable and any discriminant function.

In conclusion, three types of interactions (synergistic, additive and negative synergistic effects) were observed, synergism being the most abundant effect. $M$. oreades is present in the best mixtures while $C$. cibarius is the mushroom present in the worst mixtures. In the individual assays, despite the very good results obtained for $M$. oreades, the highest phenolic content and antioxidant activity was observed for $B$. edulis. Regarding discriminant analysis, the individual species proved to have distinctive features considering antioxidant activity, once a separate cluster was obtained for each species. In the case of mushroom mixtures the obtained results showed a higher homogeneity, once it was not possible to obtain a single cluster for each mixture. Actually, only the mixtures containing Cci were clearly separated, confirming that $C$. cibarius reveals a significantly lower antioxidant activity, as well as minor phenolic content.

\section{Acknowledgements}

The authors are grateful to the Foundation for Science and Technology (PPCDT/ AGR/56661/2004 project and BPD/38008/2007 grant) for financial support of this work.

Declaration of interest: The authors report no conflicts of interest. The authors alone are responsible for the content and writing of the paper.

\section{References}

Barros L, Cruz T, Baptista P, Estevinho LM, Ferreira ICFR. 2008a. Wild and commercial mushrooms as source of nutrients and nutraceuticals. Food Chem Toxicol 46:2742-2747.

Barros L, Falcão S, Baptista P, Freire C, Vilas-Boas M, Ferreira ICFR. 2008b. Antioxidant activity of Agaricus sp. mushrooms by chemical, biochemical and electrochemical assays. Food Chem 111:61-66.

Benitez E, Nogales R, Campos M, Ruano F. 2006. Biochemical variability of olive-orchard soils under different management systems. App Soil Ecol 32:221-231.

Cheung LM, Cheung PCK. 2005. Mushrooms extracts with antioxidant activity against lipid peroxidation. Food Chem 89:403-409.

Cragg GM, Newman DJ, Snader KM. 1997. Natural products in drug discovery and development. J Nat Prod 60:52-60.

Elmastas M, Isildak O, Turkekul I, Temur N. 2007. Determination of antioxidant activity and antioxidant compounds in wild edible mushrooms. J Food Comp Anal 20:337-345.

Ferreira ICFR, Barros L, Abreu RMV. 2009. Antioxidants in wild mushrooms. Curr Med Chem 16: $1543-1560$ 
Grabley S, Thiericke R. 1999. Bioactive agents from natural sources: Trends in discovery and application. Adv Biochem Eng Biotechnol 64:101-154.

Harvey A. 2000. Strategies for discovering drugs from previously unexplored natural products. Drug Discov Today 5:294-300.

Heo HJ, Kim YJ, Chung D, Kim D-O. 2007. Antioxidant capacities of individual and combined phenolics in a model system. Food Chem 104:87-92.

Hsu H-F, Houng J-Y, Chang C-L, Wu C-C, Chang F-R, Wu Y-C. 2005. Antioxidant activity, cytotoxicity, and DNA information of Glossogyne tenuifolia. J Agric Food Chem 53:6117-6125.

Kim MY, Seguin P, Ahn JK, Kim JJ, Chun SC, Kim EH, Seo SH, Kang EY, Kim SL, Park YJ, et al. 2008. Phenolic compound concentration and antioxidant activities of edible and medicinal mushrooms from Korea. J Agric Food Chem 56:7265-7270.

Lee Y-L, Jian S-Y, Lian P-Y, Mau J-L. 2008. Antioxidant properties of extracts from a white mutant of the mushroom Hypsizigus marmoreus. J Food Comp Anal 21:116-124.

Liu RH. 2004. Potential synergy of phytochemicals in cancer prevention: Mechanism of action. J Nutr 134:3479S-3485S

Magalhães LM, Segundo MA, Reis S, Lima JLFC. 2008. Methodological aspects about in vitro evaluation of antioxidant properties. Anal Chim Acta 613:1-19.

Mizuno T. 1995. Bioactive biomolecules and mushrooms: Food function and medicinal effects of mushroom fungi. Food Rev Int 11:7-21.

Newman DJ, Cragg GM, Snader KM. 2000. The influence of natural products upon drug discovery. Nat Prod Rep 17:215-234.

Philpott M, Gould KS, Lim C, Ferguson LR. 2004. In situ and in vitro antioxidant activity of sweetpotato anthocyanins. J Agric Food Chem 52:1511-1513.

Pinelo M, Manzocco L, Nuñez MJ, Nicoli MC. 2004. Interaction among phenols in food fortification: Negative synergism on antioxidant capacity. J Agric Food Chem 52:1177-1180.

Puttaraju NG, Venkateshaiah SU, Dharmesh SM, Urs SM, Somasundaram R. 2006. Antioxidant activity of indigenous edible mushrooms. J Agric Food Chem 54:9764-9772.

Tsai SY, Tsai HL, Mau JL. 2007. Antioxidant properties of Agaricus blazei, Agrocybe cylindracea, and Boletus edulis. LWT Food Sci Technol 40:1392-1402.

Vinson JA, Su X, Zubik L, Bose P. 2001. Phenol antioxidant quantity and quality in foods: fruits. J Agric Food Chem 49:5315-5321.

Wang W, Weng X, Cheng D. 2000. Antioxidant activities of natural phenolic components from Dalbergia odorifera. Food Chem 71:45-49.

Wasser SP, Weis A. 1999. Medicinal properties of substances occurring in higher Basidiomycetes mushrooms: Current perspectives [review]. Int J Med Mushrooms 1:31-62.

Zhou S, Gao Y, Chan E. 2005. Clinical trials for medicinal mushrooms: Experience with Ganoderma lucidum (W. Curt.:Fr.) Lloyd (Lingzhi mushroom). Int J Med Mushrooms 7:111-112. 